\title{
An Analysis of UAE Student Perspectives on Teachers and Coursework
}

\author{
Barbara Harold \\ Zayed University, UAE
}

Over the last four years students in Emirati higher education institutions have been encouraged to contribute an online article to this journal about the impact of a particular course on their life and learning. This article analyzes ten such articles to see what 'message' they might contain for faculty.

The articles concerned are:

The secret of my success: was it the textbook or the news? - Ahlam Hassan Al-Marzouqi

The meaning of learning - Aisha Al-Hamiz Al-Suwaidi

Become a designer with COM 204 - Hind Al-Ateeqi

First course in Global Studies - Fatma Al Hammadi

A course in Organizational Behaviour - Abdullah Al-Banna

It was not about HTML - Lateefa Al-Mansoori

A course for life - Maimouna Al Alawi

The impact on my study and personal life of Middle Childhood \& Adolescent Development - Fatema Abdullatif

Fasten your seat belts! - Asma Ali Chookah

Lighting the fire: teaching is about learning-Sarah Abdulla Al Awadhi

The courses the students wrote about cover a range of disciplines and included Communications (4), Business (2), Education (2) Health Sciences (1), Social and Behavioural Sciences (1) and Colloquy (General Education) (1). The brief for the authors was to write about a 'course where they had learned a lot'. While most titles used were simply descriptive (e.g. A course in Organizational Behaviour, First course in Global Studies), two authors used metaphor (e. g. Fasten your seat-belts and Lighting the fire).

The content of the articles was wide-ranging and covered seven common themes: description of course content and relevance, course materials, learning style, specific skills developed, the role of the teacher (expectations, attitude, personality, strategies) the role of the student (attitude, expectations) and assessment.

I analyzed the articles to see what aspects of teaching and learning had attracted attention. The main focus of the articles included skills (4) course content (2) relevance to life (2) teacher strategies (1) and assessment (1). When looking at the secondary focus a slightly different pattern occurred including teacher or teacher strategies (4) skills (3) and relevance to life (3). Overall the elements of the course that received the most focus in the student commentaries were skills developed, teacher characteristics and strategies, followed by relevance of the course to the students' lives.

A closer analysis of their discussion of particular skills they had learnt provided a sharper focus on what they valued in this aspect. The development of critical thinking skills was the most frequently mentioned 
skill with half of the authors mentioning this. New skills in technology use (e.g. Photoshop, web design) and information literacy were mentioned by a similar number. Four of the group commented that they had learnt effective research skills in courses. Other skills identified across the articles, but with fewer mentions, included communication skills, working in groups, asking questions, time management, making presentations and text analysis. Many of the writers provided concrete examples of how the skills had been of use to them during the course.

Teacher characteristics and strategies received a lot of attention throughout the articles. Affective characteristics were identified by several writers. One writer commented for example about how a teacher had helped her develop courage and self confidence and another noted that her teacher made the course enjoyable and easy, encouraged students to come to his office and "never sent us away" (AlMansoori, 2007). A third author said that her teacher always showed pleasure in student success and a fourth commented about how her teacher was open, honest and helpful and built an environment of trust, confidence and enjoyment.

The majority of authors identified particular teaching strategies used by their course professors that helped students achieve success. These varied a little according to the content of the course but several were common across the courses. According to the articles the most effective teachers knew their material well and came to class well prepared. Their lessons were carefully structured involving review of previous material and linking of new material to previous learning or to aspects of the students' lives. They provided opportunities for student control over learning through research, new skills, projects, and team work. Good teachers provided feedback to the students and encouraged them to practice, reflect, analyze and ask questions if they weren't sure.

Two of the authors discussed how particular teachers had built course content around real events. For example, Al-Mansoori (2007) commented in detail about how her economics teacher had sometimes moved away from the textbook and used television, websites and real world problems or events to connect the course theories to specific economic issues.

An analysis of the commentary about teaching strategies indicated that the student writers appreciated opportunities to be independent learners and to do projects and presentations. However two cautioned that it was still important for the teacher to provide some structure and guidance and not let class members 'get lost'. This was important for one writer who commented that although a teacher must give students a chance to think critically and become independent, she must not leave them to depend totally on themselves as if a learner has built up a set of 'wrong' ideas (such as in science concepts) it is very difficult to change the first wrong idea.

Writing the article required that the authors commented on how the course had impacted their lives and again there were wide-ranging perspectives on this aspect. Some commented on how their view of themselves as a learner had changed (e.g. "COM 125 is the course in which I discovered myself" (Chookah, 2005); "Never think that your abilities are limited and do not be shy about your thoughts" (ibid); "As a result of building trust and confidence, we were more 'at-home' in the class which helped us unwind and reveal parts of ourselves and therefore understand ourselves better" (Al-Haj, 2005).

Others commented on how the course had impacted their personal health and well being. For example, a student writing about a human development course topic on obesity said she now encouraged her younger brothers to do physical activity instead of watching television a lot and that she had started walking more herself to provide a better role model for her brothers (Al-Thawadi, 2006). Similarly, another student commented about her human physiology course that she had learned to 'treat her body like a friend' and that she had also taught other family members about the ideas from the course 
to encourage a healthier lifestyle (Al-Alawi, 2006). Two students spoke about how their analysis and judgment of situations had improved, e.g: "I have learned not to judge bad behavior because we need to know the facts" (Al-Thawadi, 2006); "This course has helped me in understanding people's behavior... how to accept change and help others to do so" (Al-Banna, 2007); "After this course I became less prone to judge others and more able to understand others" (Al-Haj, 2005).

Some of the courses had impacted student perspectives about global issues. For example Al-Marzouqi (2009) said of the Macroeconomics course: "Now I can think globally, analyze things internationally and create solutions for economic problems". Similarly, Al-Hammadi (2007) noted that COL 150 had "made [her] aware of the global issues around us".

The articles indicated clearly to me that the impact of the identified courses was wide ranging; something that course teachers may not always be aware of as they go about their professional work. These writers showed how they had grown as learners and matured as young adults through their interaction with their teachers and the course content. A tone of respect and warmth showed in many of the articles as the authors talked about the personal characteristics and teaching strategies of the instructors. In summary the students provided a sound endorsement of the value of many elements of the undergraduate programs at these institutions.

\section{Author}

Dr. Barbara Harold is a Professor in the College of Education, Zayed University, Dubai. 